\title{
AN UPDATE IN THE SEPARATION OF NATURAL FROM SYNTHETIC AMETHYSTS
}

\section{Karampelas S. ${ }^{1,2}$, Fritsch E. ${ }^{2}$, Zorba T. ${ }^{3}$, Paraskevopoulos K. M. ${ }^{3}$, and Sklavounos $\mathbf{S}^{1}$}

${ }^{1}$ Department of Geology, Laboratory of Mineralogy - Petrology - Economic Geology, Aristotle, University of Thessaloniki, 54124 Thessaloniki, Greece (corresponding author: steka@physics.auth.gr)

${ }^{2}$ Université de Nantes, Nantes Atlantique Universités, CNRS, Institut des Matériaux Jean Rouxel (IMN), Laboratoire de Physique des Matériaux et Nanostructures- 2 rue de la Houssiniere, UMR6502, BP32229, F-44322 Nantes Cedex 3 France

${ }^{3}$ Physics Department, Solid State Physics Section, Aristotle University of Thessaloniki, 54124 Thessaloniki, Greece

\begin{abstract}
Since the first synthetic amethyst was commercially manufactured about 30 years ago, the separation from natural material has been difficult for gemologists. Even today, the separation of natural from hydrothermally grown in $\mathrm{K}_{2} \mathrm{CO}_{3}$ synthetic amethyst is still an issue. With only the help of classical gemological criteria (such as inclusions, twinning and color zoning) it is difficult to separate synthetic stones from their natural counterparts. The separation problem is even more complex in the case of the highest quality (and value) of amethysts presenting neither inclusion nor twinning nor color zoning. IR absorption spectra of amethyst in the region of the $X$ $\mathrm{OH}$ group stretching (particularly from 3000 to $3900 \mathrm{~cm}^{-1}$ ) reveal several bands that have been used for the separation of natural from synthetic amethyst. Using a resolution at $0.5 \mathrm{~cm}^{-1}$ the $3595 \mathrm{~cm}^{-1}$ band is present in all natural amethyst and in some rare synthetic ones. When present in synthetic amethysts, its full width at half maximum (FWHM) is about $7 \mathrm{~cm}^{-1}$, whereas it is about $3.3 \mathrm{~cm}^{-1}$ in all naturals. This new criterion worked for all of our samples.
\end{abstract}

Key words: gems, infrared spectroscopy, FWHM.

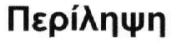

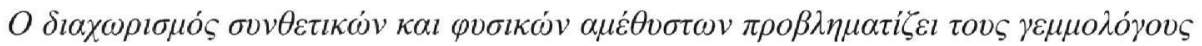

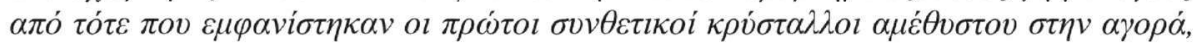

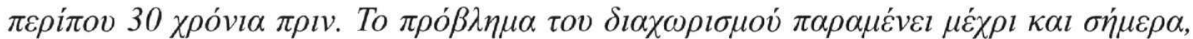

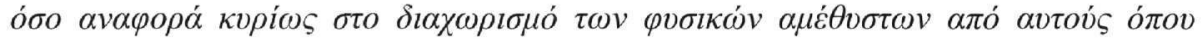

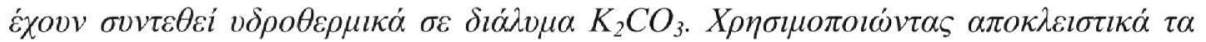

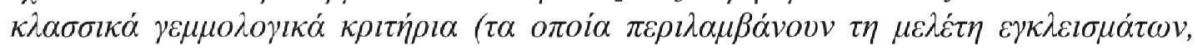

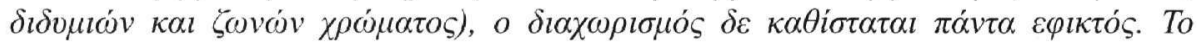

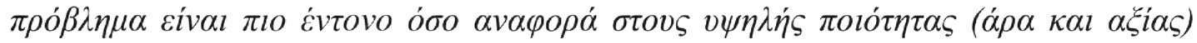

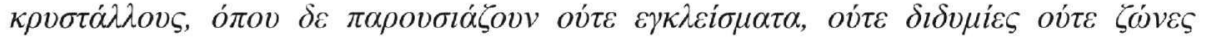




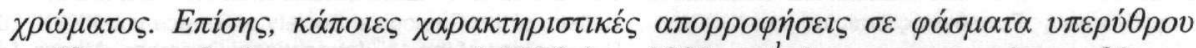

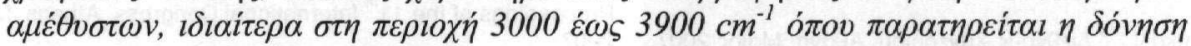

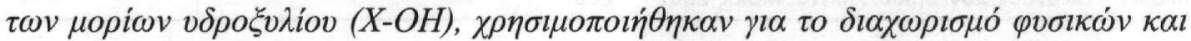

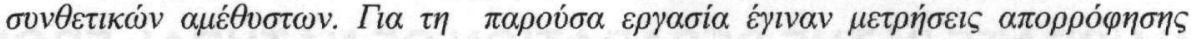

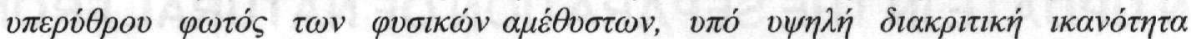

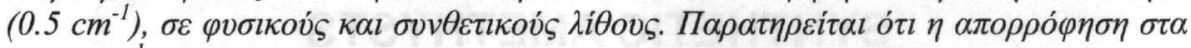

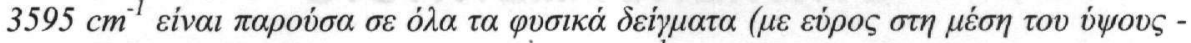

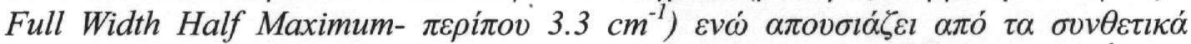

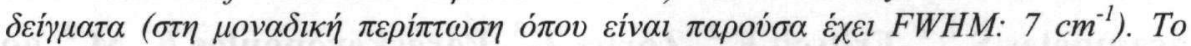

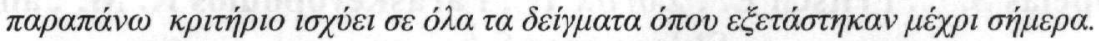

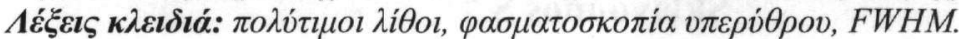

\section{Introduction}

Amethyst exceptional color draws the attention of gemologists, mineralogists and general public alike. Because of this it is an important material of the jewelry industry. Today's major problem is the presence of significant quantities of synthetic amethyst on the market. These amethysts should cost less than their natural counterparts. With only the help of classical gemological techniques (such as the study of inclusions, twinning and color zoning) it is difficult to separate synthetic stones from their natural counterparts (Fritsch et al. 1987a, Fritsch et al. 1988a, Fritsch et al. 1995, Notari et al. 2001). The separation issue is compounded even more in the case of the highest quality (and value) of amethysts, which typically presents neither inclusion nor twinning or color zoning. The impact of this is a lack of confidence from the buyers and has prompted much research into identifying the synthetic material with certainty. In particular, arguments based on the presence or the absence of certain infrared absorption bands proved promising (Fritsch et al. 1987a, Fritsch et al. 1988a, Fritsch et al. 1995, Notari et al. 2001, Smaali, 1998, Zecchini et al. 1999, Karampelas et al. 2005). The most recent argument (Karampelas et al. 2005) is tested in this paper on a large number of samples.

\section{Background}

\subsection{Natural amethyst}

Quartz has many colored varieties. The most common varieties, which are used as gems are: colorless quartz (rock crystal), violet-purple (amethyst), yellow (citrine), pink quartz and green quartz (prasiolite). Amethyst color is caused by $\mathrm{O}^{2-} \rightarrow \mathrm{Fe}^{4+}$ charge transfer, the rarer $4^{+}$valence of iron being due to irradiation (Fritsch et al. 1988b). Their point group is 32 and their space group is $P 3_{1} 2, P_{2} 2$. The most intense color is concentrated in the major rhombohedron and occasionally in the minor rhombohedron (Balitsky, 1981). Like other varieties of quartz, amethysts can be found in various geological environments. They occur in geodes of basaltic rocks e.g. Brazil (Rio Grande do Sul), Uruguay (Artigo) etc. Amethyst crystals can also be found in pegmatite e.g. in Mexico (Vera Cruz), Madagascar etc. In some rare cases they form in alluvial deposits, as in Minas Gerais in Brazil. Countries with the most important gem quality production of amethysts used in jewelry, are presented in Table 1 (Webster 1975).

\subsection{Synthetic amethysts}

With the growing interest on synthetic amethyst, scientist tried to synthesize crystals of higher quality, without cracks etc. The hydrothermal method is issued exclusively either in a near neutral $\mathrm{NH}_{4} \mathrm{~F}$ or in an alkaline $\mathrm{K}_{2} \mathrm{CO}_{3}$ solution (Balitsky et al. 1975, Khadzi et al. 1975). The vast majority of synthetic amethysts present on the market today is grown in $\mathrm{K}_{2} \mathrm{CO}_{3}$ solutions (Fritsch et al. 1995, Balitsky 2004b). 
Table 1 - Countries or states with the most important production of gem-quality amethysts

\begin{tabular}{|c|c|}
\hline Continent & Country or State \\
\hline Africa & South Africa, Madagascar, Namibia, Zambia, Zimbabwe \\
\hline North America & Arizona, Canada, Colorado, Maine, New Jersey \\
\hline South America & Brazil, Bolivia, Mexico, Uruguay \\
\hline Asia & China, India, Japan, Korea \\
\hline Europe & Russia \\
\hline Oceania & Australia \\
\hline
\end{tabular}

\subsection{Separation of natural from synthetic amethysts}

The first synthetic amethyst crystals were commercially synthesized since 1975 (Bariand et al. 1998). Gemologists used classical gemology (twinning, inclusions and color zoning) as well as laboratory methods (FTIR) to identify this material.

\subsubsection{Classical gemology}

\subsubsection{Twinning}

To use this test, only a polariscope and an immersion cell are needed. The test popularized by Schmetzer in 1985, relies on the fact that natural amethysts are polysynthetically (Brazil law) twinned, whereas synthetic amethysts grown are not (Crowningshield et al. 1986, Fritsch et al. 1987a, Fritsch et al. 1988). If twinning is observed when looking down an amethyst's optic axis under crossed polarizers, that gem can be identified as natural. Only synthetic amethysts grown in $\mathrm{NH}_{4} \mathrm{~F}$ never present twinning. Synthetic amethysts grown in $\mathrm{K}_{2} \mathrm{CO}_{3}$ may present twinning; it appears in an irregular (flame-like twin pattern) form (Crowningshield et al. 1986, Fritsch et al. 1989, Notari et al. 2001). By contrast, natural amethysts twinning forms a characteristic angle of $60^{\circ}$ or $120^{\circ}$ (Crowningshield et al. 1986). However, natural amethysts (from Altiplano, Bolivia) were found with twinning of different angles (Notari et al. 2001). Fritsch and Koivula (1989) show that twinning in synthetic amethyst sometimes cannot be separated from that present in the natural. Additionally, natural amethysts that do not present twinning were found (Crowningshield et al. 1986, Fritsch et al. 1987a, Fritsch et al. 1988, Notari et al. 2001). Thus, it is obvious that this method is not always effective.

\subsubsection{Inclusions}

Another classical gemological method useful for the separation is the examination of inclusions. For this method the microscopic study is sufficient. Natural amethysts can contain the inclusions cited below (Gübelin et al. 1986, Fritsch et al. 1987a, Fritsch et al. 1988):

- blood-red plates of lepidococite,

- brooms or needles of goethite,

- circular concretions of orange limonite and black hematite,

- negative crystals with fluids inclusions,

- comet-like stringers of numerous tiny two-phase inclusions.

Typical inclusions in synthetic amethysts are:

- synthetic eucryptite "breadcrumbs", 
- spike-shaped two-phase (liquid and gas) inclusions, because of the hydrothermal origin (not always synthetic).

Synthetic eucryptite can be found in some rare natural stones (Crowningshield et al. 1986). When inclusions are present, they are a very good way to separate natural from synthetic amethysts, but it is not generally the case of high value amethysts, which often contain no inclusions.

\subsubsection{Color zoning}

Color zoning is seen using a microscope, with diffused transmitted light. When color zoning is seen in a synthetic amethyst, it is limited to darker and lighter shades of purple. The color zoning in natural amethysts is typically straight or angular in two or three directions and might consist of purple and violetish blue zones, sometimes contrasting with near-colorless zones (Crowningshield et al. 1986). A near-coloress zone has not been reported in a synthetic amethyst (Fritsch et al. 1987a, Fritsch et al. 1988). Wavy color zoning is a common feature of synthetic amethysts and is rarely seen in natural stones. Although color zoning alone is not enough to ascertain the origin of a stone, study of zones is a useful auxiliary test.

\subsubsection{Laboratory method (FTIR)}

Infrared spectroscopy is a powerful tool for gem identification and research. Absorption peaks of a gem material in the infrared region of the electromagnetic spectrum are due to vibrations of molecules in the crystal structure. They can be used to separate one gem from another or natural from synthetics gems or to detect some treatments (Fritsch et al. 1987b).

Infrared absorption in the region of X-OH group stretching mode (particularly from 3000 to 3900 $\mathrm{cm}^{-1}$ ) has been suggested as a useful method to separate synthetic from natural amethysts (Zecchini 1979, Fritsch et al. 1987a, Fritsch et al.1988, Fritsch et al. 1995, Smaali 1998, Zecchini et al. 1999, Notari et al. 2001, Balitsky et al. 2004 a, b). The identification of crystals grown in $\mathrm{NH}_{4} \mathrm{~F}$ solution is easy through the observation of their specific infrared absorption bands at 3630 , 3664 and $3684 \mathrm{~cm}^{-1}$ (Balitsky et al. $2004 \mathrm{a}, \mathrm{b}$ ). In the case of crystals grown in $\mathrm{K}_{2} \mathrm{CO}_{3}$ (referred to as simply "synthetic amethyst" thereafter) separation is more difficult (Zecchini 1979, Fritsch et al. 1987, Fritsch et al.1988, Fritsch et al. 1995, Smaali 1998, Zecchini et al. 1999, Notari et al. 2001, Karampelas 2002, Karampelas et al. 2004, Balitsky et al. 2004 a, b). Generally, synthetic and natural amethysts have almost the same spectrum in this region. Both of them present two absorption peaks at 3585 and $3612 \mathrm{~cm}^{-1}$, due to the presence of $\mathrm{OH}^{-}$in the quartz structure (Kats 1962). A band at $3543 \mathrm{~cm}^{-1}$ occurs rarely in natural amethysts but is observed in the overwhelming majority of synthetic ones. Furthermore, it has been proposed that the $3595 \mathrm{~cm}^{-1}$ absorption peak is present in natural amethyst only (Zecchini 1979, Smaali 1998, Zecchini et al. 1999).

Balitsky and colleagues (2004 a, b) have demonstrated that the $3543 \mathrm{~cm}^{-1}$ band is not as rare in natural amethysts as commonly believed and it may be absent in some synthetic amethysts. In addition, they have demonstrated that this band reflects certain crystal growth conditions common in both natural and synthetic amethyst. Namely, this peak is indirectly related to the negative rhombohedron growth sector. This sector dominates in most commercial synthetic amethyst, but is minor to absent in natural amethyst crystals. Therefore, the absorption band is much less common in natural amethyst but is present in the majority of the synthetic samples because of their different growth conditions, thus it cannot be considered a characteristic absorption feature of synthetic amethyst. Moreover, the $3595 \mathrm{~cm}^{-1}$ band may be present in some synthetic amethysts (Karampelas 2002, Karampelas et al. 2004, Karampelas et al.arampelas et al. 2005) and absent from some natural ones (Kitawakiet al. $2004 \mathrm{a}, \mathrm{b}$ ). Measurements on selected samples (these samples were selected because they violated the separation criteria previously proposed), using (non-standard) high resolution of $0.5 \mathrm{~cm}^{-1}$, have shown that separation can be performed based on the presence and full width at half maximum (FWHM) of the $3595 \mathrm{~cm}^{-1}$ band (Karampelas et al. 2005). More precisely, at that resolution, the $3595 \mathrm{~cm}^{-1}$ band has its true shape and it was documented in natural amethysts and rarely in the synthetics. If this band is present in synthetic amethysts its FWHM is 
$7 \mathrm{~cm}^{-1}$ approximately twice that measured in natural amethysts (about $3 \mathrm{~cm}^{-1}$ ) (Karampelas et al. 2005).

As observed by previous authors (Smaali 1998, Zecchini et al. 1999), there is no direct correlation between the intensity of the color and the infrared absorbance in the region of X-OH group stretching (which apparently depends mostly on water content). In most cases, the orientation of the beam relative to the crystallographic axes, typically does not induce a very significant change in intensity (Smaali 1998, Zecchini et al. 1999, Balitsky et al. 2004b, Karampelas 2002, Karampelas et al. 2005). So the relevant peaks can be detected in spectra taken in random orientations, which is useful for the identification of faceted gems, for which crystallographic orientation is typically unknown, and sometimes hard to ascertain.

\section{Materials and Methods}

The current study is based on the measurement of the intensity and shape, of bands useful for amethyst separation, on 30 natural (Table 2) and 10 synthetic (Table 3 ) amethysts at resolutions of 4 and $0.5 \mathrm{~cm}^{-1}$. Measurements on crystallographically oriented crystals (cut parallel and perpendicular to c-axis) were obtained on a Bruker 113v FTIR spectrometer, in vacuum, at the Physics Department of Aristotle University of Thessaloniki, Greece. Measurements on faceted stones, took place on a FTIR Bruker Vertex 70 at the IMN (Institut des Matériaux Jean Rouxel, France) using a diffuse reflectance accessory as a beam condenser. To obtain a good signal to noise ratio, in many cases long measurements were necessary (see "scans" in Tables 1 and 2; a measurement of 1024 scans at $0.5 \mathrm{~cm}^{-1}$ resolution takes about $1 \mathrm{~h}$ and $30 \mathrm{~min}$.). The full width at half maximum (FWHM) of the $3595 \mathrm{~cm}^{-1}$ band is measured by a classic method: a linear background passing through the bottom of the transmission windows on either side of the peak is subtracted, the half-height is determined relative to this linear background, and the half-width is measured at half height parallel to the linear background.

\section{Results}

Infrared absorption spectra in the range $3500-3640 \mathrm{~cm}^{-1}$ of various test amethysts are presented in figures 1 to 5 . The spectra corresponding to the two different resolutions are stacked, and offset in absorbance for clarity. In all figures, the upper spectra are taken at a resolution of $0.5 \mathrm{~cm}^{-1}$, and the lower ones with a $4 \mathrm{~cm}^{-1}$ resolution. The intensities of the peaks vary from one stone to another, but are unaffected by color intensity.

\subsection{Natural amethysts}

Table 1 presents the natural amethysts tested:

- The 3585 and $3614 \mathrm{~cm}^{-1}$ bands are present in all samples (e.g. Figs from 1 to 3 ).

- The $3543 \mathrm{~cm}^{-1}$ absorption band is weak but distinct in some of the samples (e.g. Fig. 1).

- The $3595 \mathrm{~cm}^{-1}$ absorption band, although clearly seen in majority of our samples at $4 \mathrm{~cm}^{-1}$ resolution (e.g. Fig. 2), is hard to make out in some cases (Figs 1 and 3). At $0.5 \mathrm{~cm}^{-1}$ resolution, this absorption band is well resolved in all of our natural samples (Figs 1-3).

The full width at half maximum (FWHM) of the $3595 \mathrm{~cm}^{-1}$ absorption band for all of our natural samples is about $3.3 \mathrm{~cm}^{-1}\left( \pm 0.6 \mathrm{~cm}^{-1}\right)$ (see Figs 1 to 3 and Table 2). 
Table 2 - Samples of natural amethysts from different countries, with their weight (or dimension for the oriented crystals), the FWHM of the $3595 \mathrm{~cm}^{-1}$ absorption band and the number of scans. Samples with unknown origin "prove" their natural nature under the microscope (inclusions, twinning etc.). Results for the samples with stars have been already published (Karampelas et al. 2005)

\begin{tabular}{|c|c|c|c|}
\hline $\begin{array}{c}\text { Country or State of } \\
\text { origin/Type }\end{array}$ & $\begin{array}{c}\text { Weight (ct.) or } \\
\text { dimensions } \\
(\mathrm{mm})\end{array}$ & $\begin{array}{c}\text { FWHM }\left(\mathrm{cm}^{-1}\right) \\
\text { of } 3595 \mathrm{~cm}^{-1} \\
\text { band }\end{array}$ & $\begin{array}{c}\text { Scans at } 4 / 0.5 \mathrm{~cm}^{-1} \\
\text { resolution }\end{array}$ \\
\hline Bolivia (Altiplano)/oriented & $6.5 \times 3.8$ & 3 & $64 / 128$ \\
\hline France (St. Raphael)/oriented & $3.5 \times 3.2$ & 3 & $64 / 128$ \\
\hline Arizona (Four peaks)/oriented & $4.4 \times 3.8$ & 3 & $64 / 128$ \\
\hline * Bolivia (Anahi mine)/oriented & $5.1 \times 4.5$ & 3 & $64 / 128$ \\
\hline * Mexico (Vera Cruz)/oriented & $6.1 \times 5.1$ & 3 & $64 / 128$ \\
\hline * Namibia (Platveld)/oriented & $15.8 \times 9.8$ & 3 & $64 / 128$ \\
\hline * Madagascar/ oriented & $3.2 \times 2.3$ & 3 & $64 / 256$ \\
\hline Arizona (Four peaks)/faceted & 3.4 & 3 & $128 / 1024$ \\
\hline Bolivia (Anahi mine)/faceted & 4.1 & 3.2 & $128 / 1024$ \\
\hline Zambia (Solwezi)/faceted & 3.75 & 3.5 & $128 / 1024$ \\
\hline Unknown/faceted & 4.45 & 2.9 & $128 / 1024$ \\
\hline Unknown/faceted & 3.6 & 3.2 & $256 / 1024$ \\
\hline Unknown/faceted & 2.85 & 3.9 & $256 / 1024$ \\
\hline Unknown/faceted & 1.4 & 3.3 & $256 / 1024$ \\
\hline Unknown/faceted & 1.1 & 3.3 & $256 / 1024$ \\
\hline Unknown/faceted & 1.9 & 3.4 & $128 / 1024$ \\
\hline Unknown/faceted & 1.3 & 3.2 & $128 / 1024$ \\
\hline Unknown/faceted & 1.85 & 3.9 & $128 / 1024$ \\
\hline Unknown/faceted & 3.45 & 3.2 & $128 / 1024$ \\
\hline Unknown/faceted & 2.35 & 3.3 & $128 / 1024$ \\
\hline Unknown/faceted & 1.35 & 3.2 & $128 / 512$ \\
\hline Unknown/faceted & 2.6 & 3.4 & $128 / 1024$ \\
\hline Unknown/faceted & 1.25 & 3.2 & $128 / 1024$ \\
\hline Unknown/faceted & 1.6 & 3.9 & $128 / 1024$ \\
\hline Unknown/faceted & 2.25 & 3.2 & $128 / 1024$ \\
\hline Unknown/faceted & 0.45 & 2.7 & $128 / 1024$ \\
\hline Unknown/faceted & 1.15 & 3.7 & $128 / 512$ \\
\hline Unknown/faceted & 2 & 3.7 & $128 / 512$ \\
\hline Unknown/faceted & 2.55 & 3.7 & $128 / 512$ \\
\hline Unknown/faceted & 3.05 & 3.2 & $256 / 1024$ \\
\hline
\end{tabular}




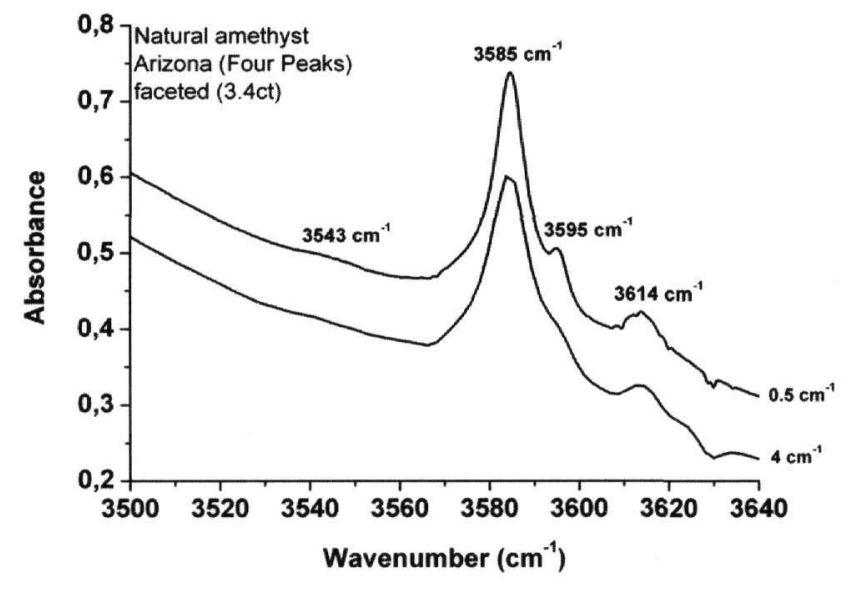

Figure 1 - IR absorption with resolutions of $4 \mathrm{~cm}^{-1}$ (lower spectrum) and $0.5 \mathrm{~cm}^{-1}$ (upper spectrum) for a randomly oriented faceted natural amethyst (3.4 ct.) from Arizona (Four Peaks). The $3595 \mathrm{~cm}^{-1}$ band is difficult to de detected in spectra acquired at $4 \mathrm{~cm}^{-1}$, whereas it is well distinguished at $0.5 \mathrm{~cm}^{-1}$ resolution (FWHM: $3 \mathrm{~cm}^{-1}$ ). The band at $3543 \mathrm{~cm}^{-1}$ is also observed

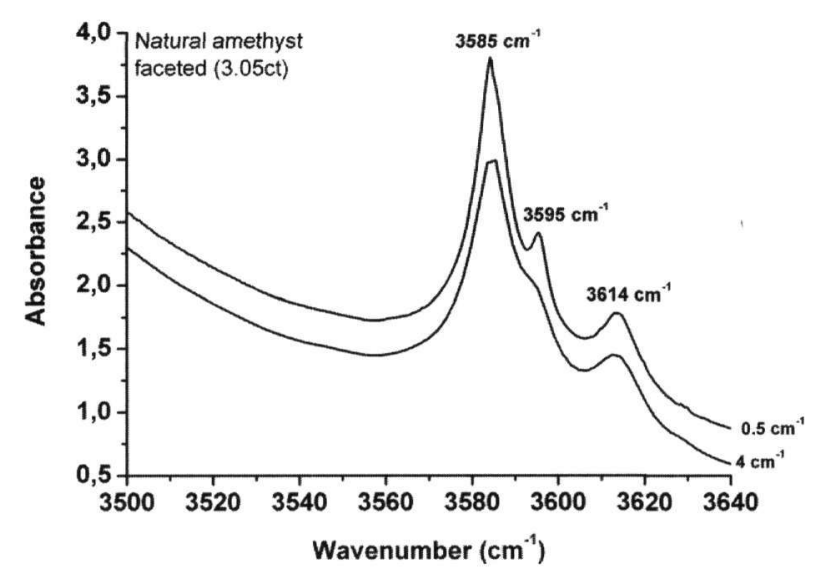

Figure 2 - IR absorption with resolutions of $4 \mathrm{~cm}^{-1}$ (lower spectrum) and $0.5 \mathrm{~cm}^{-1}$ (upper spectrum) for a randomly oriented faceted natural amethyst $\left(3.05 \mathrm{ct}\right.$.). The $3595 \mathrm{~cm}^{-1}$ band is more difficult to be detected in spectra acquired at $4 \mathrm{~cm}^{-1}$ than at $0.5 \mathrm{~cm}^{-1}$ resolution (FWHM: $3.2 \mathrm{~cm}^{-1}$ )

\subsection{Synthetic amethysts}

Table 3 presents the synthetic amethysts tested:

- The absorption peaks at 3543,3585 and $3614 \mathrm{~cm}^{-1}$ bands are present in all samples (e.g. Figs 4 and 5).

- The $3595 \mathrm{~cm}^{-1}$ absorption band is detected in only one of the synthetic samples. The FWHM of this peak at a resolution of $0.5 \mathrm{~cm}^{-1}$ is about $7 \mathrm{~cm}^{-1}\left( \pm 1 \mathrm{~cm}^{-1}\right)$ (Table 3). 


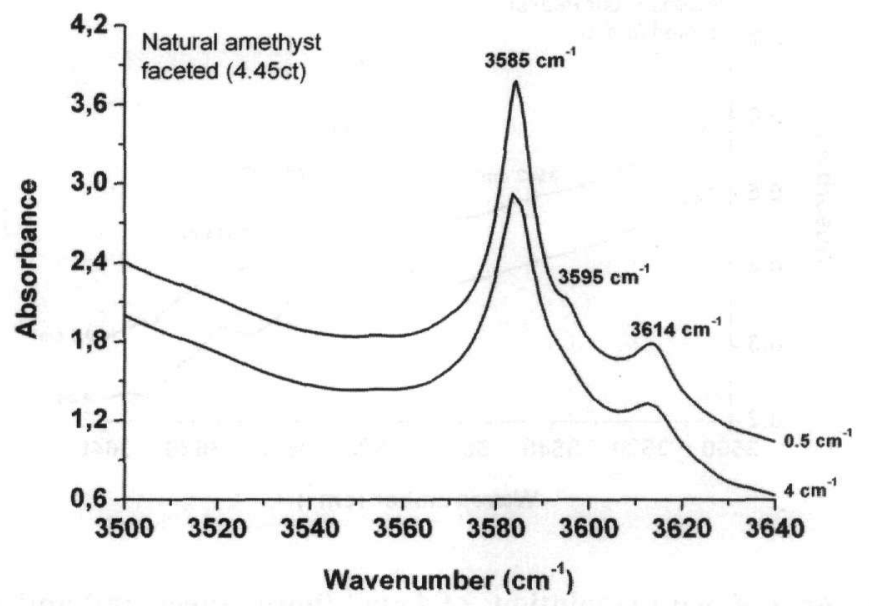

Figure 3 - IR absorption with resolutions of $4 \mathrm{~cm}^{-1}$ (lower spectrum) and $0.5 \mathrm{~cm}^{-1}$ (upper spectrum) for a randomly oriented faceted natural amethyst $\left(4.45 \mathrm{ct}\right.$ ). The $3595 \mathrm{~cm}^{-1}$ band is barely seen in spectra acquired at $4 \mathrm{~cm}^{-1}$, whereas it is well discriminated at $0.5 \mathrm{~cm}^{-1}$ resolution (FWHM: $2.9 \mathrm{~cm}^{-1}$ )

Table 3 - Samples of synthetic amethysts grown in a $\mathrm{K}_{2} \mathrm{CO}_{3}$ solution from different countries with their weight (or dimensions for the oriented crystals), the FWHM of the $3595 \mathrm{~cm}^{-1}$ absorption band (if it exists) and the number of scans. Results for the samples with the stars have been already published (Karampelas et al. 2005)

\begin{tabular}{|c|c|c|c|}
\hline $\begin{array}{c}\text { Country or State of } \\
\text { origin/Type }\end{array}$ & $\begin{array}{c}\text { Weight (ct.) or } \\
\text { dimensions } \\
(\mathbf{m m})\end{array}$ & $\begin{array}{c}\text { FWHM }\left(\mathbf{c m}^{-\mathbf{1}}\right) \\
\text { of } \mathbf{3 5 9 5} \mathbf{~ c m}^{-1} \\
\text { band }\end{array}$ & $\begin{array}{c}\text { Scans at 4/0.5 } \mathbf{~ c m}^{-1} \\
\text { resolution }\end{array}$ \\
\hline$*$ Russia/oriented & $3.4 \times 2$ & 7 & $64 / 128$ \\
\hline *Russia/oriented & $4.5 \times 2.9$ & - & $64 / 512$ \\
\hline Russia/faceted & 20 & - & $128 / 1024$ \\
\hline Russia/faceted & 29.25 & - & $128 / 1024$ \\
\hline Russia/faceted & 8.45 & - & $128 / 1024$ \\
\hline Russia/faceted & 8.85 & - & $128 / 1024$ \\
\hline U.S.A. -Sawyer-/faceted & 0.65 & - & $128 / 512$ \\
\hline U.S.A. -Sawyer-/faceted & 0.6 & - & $128 / 256$ \\
\hline U.S.A. -Sawyer-/faceted & 0.55 & - & $128 / 256$ \\
\hline Unknown/ faceted & 1.55 & - & $512 / 1024$ \\
\hline
\end{tabular}




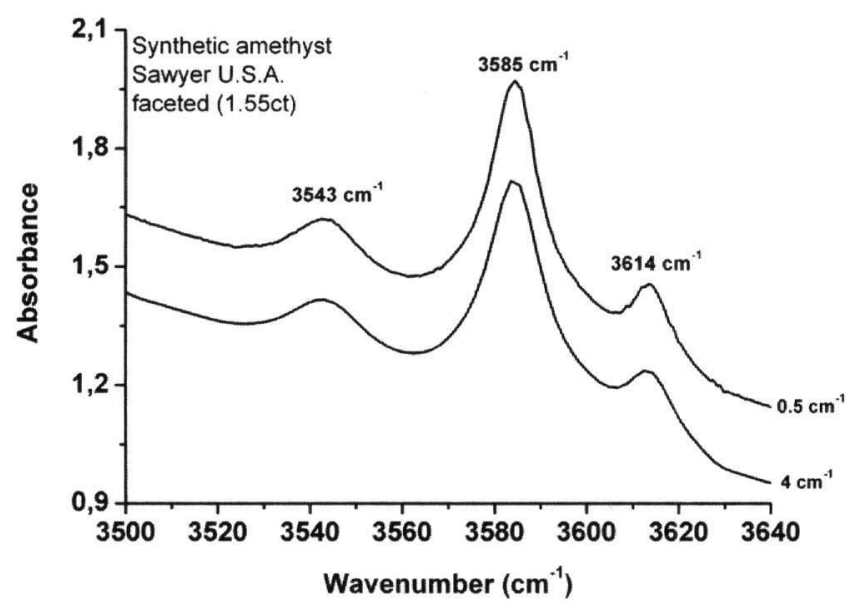

Figure 4 - IR absorption with resolutions of $4 \mathrm{~cm}^{-1}$ (lower spectrum) and $0.5 \mathrm{~cm}^{-1}$ (upper spectrum) for a randomly oriented faceted synthetic amethyst (1.55 ct.) from U.S.A. (Sawyer) grown in a $\mathrm{K}_{2} \mathrm{CO}_{3}$ solution. $\mathrm{No}$ band at $3595 \mathrm{~cm}^{-1}$ is observed. The band at 3543 $\mathrm{cm}^{-1}$ is well developed

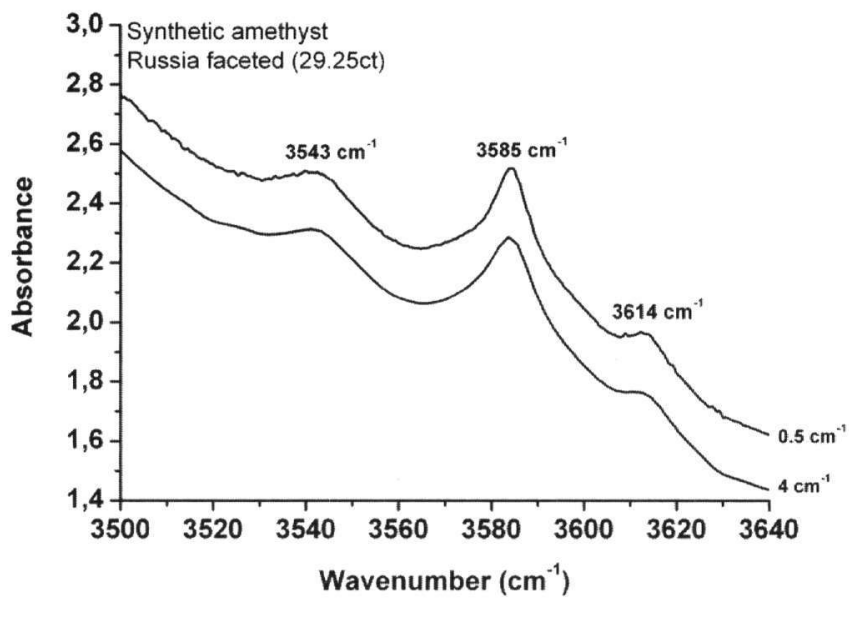

Figure 5 - IR absorption with resolutions of $4 \mathrm{~cm}^{-1}$ (lower spectrum) and $0.5 \mathrm{~cm}^{-1}$ (upper spectrum) for a randomly oriented faceted synthetic amethyst $(29.25$ ct.) from Russia grown in a $\mathrm{K}_{2} \mathrm{CO}_{3}$ solution. No band at $3595 \mathrm{~cm}^{-1}$ is observed. The band at $3543 \mathrm{~cm}^{-1}$ is well discriminated

\section{Discussion and conclusion}

The $3595 \mathrm{~cm}^{-1}$ absorption band is of the greatest interest. It reaches its true shape only at $0.5 \mathrm{~cm}^{-1}$ resolution. Therefore using a resolution of $4 \mathrm{~cm}^{-1}$ (as most laboratories), this band may be missed (e.g. Figs 1 and 3). Previous publications (Kitawaki 2002, Balitsky et al. 2004b) state that the 3595 $\mathrm{cm}^{-1}$ absorption band is absent in some natural amethysts. This could be due to inadequate resolution of the spectra. The resolution is $4 \mathrm{~cm}^{-1}$ in the case of Kitawaki's study, but is not mentioned in Balitsky's article. Therefore a resolution of $0.5 \mathrm{~cm}^{-1}$ seems necessary for the 
detection of the $3595 \mathrm{~cm}^{-1}$ peak. With such a resolution, this peak is detected in all our natural amethysts, with a FWHM of about $3.3 \mathrm{~cm}^{-1}\left( \pm 0.6 \mathrm{~cm}^{-1}\right)$.

The $3595 \mathrm{~cm}^{-1}$ absorption band is observed in one synthetic sample (Karampelas 2002, Karampelas et al. 2004, Karampelas et al. 2005). However its FWHM, at a resolution of $0.5 \mathrm{~cm}^{-1}$, is about $7 \mathrm{~cm}^{-1}\left( \pm 1 \mathrm{~cm}^{-1}\right)$ (Karampelas et al. 2005).

If amethysts of unknown origin received in a gemological laboratory, it is suggested, first of all, to observe them under a microscope. If it is not possible to identify their natural or synthetic origin using classical gemology, an infrared spectrum should be obtained at $0.5 \mathrm{~cm}^{-1}$ resolution, with a good signal to noise ratio. If the $3595 \mathrm{~cm}^{-1}$ band is absent, then the amethyst is synthetic. If the $3595 \mathrm{~cm}^{-1}$ band is present with a FWHM of about $7 \mathrm{~cm}^{-1}\left( \pm 1 \mathrm{~cm}^{-1}\right)$ the amethyst is also synthetic. It is otherwise natural $\left(3595 \mathrm{~cm}^{-1}\right.$ band with FWHM of $\left.3.3 \mathrm{~cm}^{-1} \pm 0.6 \mathrm{~cm}^{-1}\right)$.

Further research is necessary in order to explore the cause for this small difference in the infrared absorption spectrum of natural and synthetic amethysts. Previous studies (Zecchini et al. 1999) have linked the $3595 \mathrm{~cm}^{-1}$ band to the presence of boron. A systematic search for this difficult-todetect impurity in amethyst, using near non-destructive chemical analysis (e.g. Laser Ablation Inductively Coupled Plasma Mass Spectrometry -LA-ICPMS- or Laser Induced Breakdown Spectroscopy -LIBS-) might shade light on the observed differences that have been noticed.

\section{Acknowledgments}

The authors wish to thank CRG (Centre de Recherche Gemmologique), Nantes, France, for loaning the vast majority of the samples studied as well as LFG (Laboratoire Francais de Gemmologie) in Paris, France.

\section{References}

Balitsky, V.S., Khetchikov, L.N., Orlova, V.P., and Balitskaya, L.V., 1975. Process for producing an amethyst crystal, England, patent specification 1408979, filed November 28, 1973, issued October 8, 1975.

Balitsky, V.S., 1981. Gemmology of some coloured synthetic quartz, Gemmological Society of Japan, 8, 103-117.

Balitsky, V.S., Bondarenko, G.V., Balitskaya, O.V., and Balitsky, D.V., 2004a. IR spectroscopy of natural and synthetic amethysts in the $3000-3700 \mathrm{~cm}^{-1}$ region and problem of their identification, Doklady Earth Sciences, 394(1), 120-123.

Balitsky, V.S., Balitsky, D.V., Bondarenko, G.V., and Balitskaya, O.V., 2004b. The $3543 \mathrm{~cm}^{-1}$ infrared absorption band in natural and synthetic amethyst and its value in identification, Gems and Gemology, 40(2), 146-161.

Bariand, P., and Poirot, J.P., 1998. Larousse des pierres précieuses, Paris, Larousse Bordas edition, $286 \mathrm{pp}$.

Crowningshield, R., Hurlbut, C., and Fryer C.W., 1986. A simple procedure to separate natural from synthentic amethyst on the basis of twinning, Gems and Gemology, 22(3), 130-139.

Fritsch, E., and Koivula J.I., 1987a. How to tell if that amethyst is natural, Jewelers Circular Keystone, 154(7), 322-324.

Fritsch, E., and Stockton, C.M., 1987b. Infrared spectroscopy in gem identification, Gems and Gemology, 23(1), 18-26.

Fritsch, E., and Koivula, J.I., 1988a. How to tell natural amethyst, Jewelers Circular Keystone, 158 (10), 244-248. 
Fritsch, E., and Rossman, G.R., 1988b. An Update on Color in Gems. Part 3: Colors Caused by Band Gaps and Physical Phenomena, Gems and Gemology, 24(2), 81-102.

Fritsch, E., and Koivula, J.I., 1989. The growth of Brazil-twinned synthetic quartz and the potential for synthetic amethyst twinned on the Brazil law, Gems and Gemology, 25 (3), 159-164.

Fritsch, E., and McClure, S.F., 1995. Synthetic amethyst: features of new type from Russia, Jewellery News Asia, 129(3), 90-92.

Gübelin, E. J., and Koivula, J. I., 1986. Photoatlas of inclusions in Gemstones, Zurich, ABC edition, 532pp.

Karampelas, S., 2002. Absorption infrrarouge de l'améthyste, DEA Geosciences, Université de Nantes, Nantes, France, 22pp.

Karampelas, S., and Fritsch, E. 2004. Infrared absorption us a useful tool to separate natural and synthetic amethysts, Abstract of the presentation in $5^{\text {th }}$ European Conference on Mineralogy and Spectroscopy. Mitteilungen der Österreichischen Mineralogischen Gesellschaft, Band 149(1), 43.

Karampelas, S., Fritsch, E., Zorba, T., Paraskevopoulos, K.M., and Sklavounos, S., 2005. Distinguishing natural from synthetic amethyst: the presence and shape of the $3595 \mathrm{~cm}^{-1}$ peak, Mineralogy and Petrology, 85(1-2), 45-52.

Kats, A., 1961. Hydrogen in alpha-quartz, Philips Res. Rep., 279 pp.

Khadzhi, V.E, Tsyganov, M.E., Tsinober, L.I., Novozhilova, Z.V., Reshetova, G.V., Samoilovich, M.I., Butuzov, V.P., Shaposhnikov, A.A., and Lelekova, M.L., 1975. Process for producing an amethyst crystal, England, patent specification 1408383, filed January 18, 1973, issued October 1, 1975.

Kitawaki H., 2002. Natural amethysts from Caxarai mine, Brazil, with a spectrum contain an absorption peak at $3543 \mathrm{~cm}^{-1}$, The Journal of Gemmology, 28(1), 101-108.

Notari, F., Boillat, P.Y., and Grobon, C., 2001. Discrimination des améthystes et des citrines naturelles et synthétiques, Revue de gemmologie A.F.G., 141/142, 75-80.

Smaali, M., 1998. Hétérodiffusion et irradiation gamma du quartz alpha, Mémoire de thèse de doctorat, Université de Franche-Comté, Besançon, France, 134 pp.

Webster, R., 1975. Gems: their sources, descriptions and identification, Third edition, Archon Books, Hamden CT, 938 pp.

Zecchini, P., 1979. Etude de l'absorption infrarouge de quartz d'origine naturelle ou de synthèse, Revue de gemmologie A.F.G., 60, 14-18.

Zecchini, P., and Smaali, M., 1999. Identification de l'origine naturelle ou artificielle des quartz. Revue de gemmologie A.F.G., 138/139, 74-80. 